\title{
The Impact of the Morphological Characteristics of Leaves on Particulate Matter Removal Efficiency of Plants
}

\author{
Deokjoo Son ${ }^{1}$, Kwang Jin Kim ${ }^{1 *}$, Na Ra Jeong ${ }^{1}$, Hyung Gewon Yun ${ }^{1}$, Seung Won Han ${ }^{1}$, Jeongho Kim², Gyung-Ran Do², Seon \\ Hwa Lee ${ }^{1}$, and Charlotte C. Shagol ${ }^{1}$ \\ ${ }^{1}$ Urban Agriculture Division, National Institute of Horticultural \& Herbal Science, RDA, Wanju 55365, Korea \\ 2Planning and Coordination Division, National Institute of Horticultural \& Herbal Science, RDA, Wanju 55365, Korea
}

\section{ABSTRACT}

This study was conducted to find out differences in the removal efficiency of particulate matter (PM) depending on the type of plants and the morphological characteristics of leaves. A total of 12 plants were used, with three plants selected for each type of leaves (big leaf, small leaf, compound leaf, needle leaf). We measured the removed amount of PM10 and PM2.5, the structure of the abaxial leaf surface, and the weight of the wax layer of each plant. Plants with the high removal efficiency of PM included Pachira aquatica Aubl., Ardisia crenata, and Dieffenbachia 'Marianne', and plants with the low removal efficiency included Nandina domestica Thunb, Schefflera arboricola, and Quercus dentata. The abaxial leaf surface having a high removal efficiency of PM had many large wrinkles, and the abaxial leaf surface having a medium removal efficiency was flat and smooth. On the other hand, there were many fine hairs on the abaxial leaf surface with a low removal efficiency. According to the plant leaf type, the PM10 removal efficiency of plants with needle leaves was about three times higher than that of other plants. In particular, the wax layer of conifers weighed 6-24 times higher than those of other plants. The stomata of conifers were evenly distributed on the adaxial and abaxial leaf surfaces; however, the stomata of Sciadopitys verticillata appeared in the form of papillae unlike general stomata. Therefore, the removal efficiency of PM varied depending on the macro-, and micro-morphological characteristics of plant leaves such as the structure of the abaxial leaf surface, and the weight of the wax layer. Based on this research, selecting plants that are effective in reducing PM in consideration of the plant type and leaf characteristics will improve indoor air quality and decrease exposure of PM to human body.

Keywords: conifer, leaf surface structure, leaf type, wax layer weight

\section{Introduction}

Particulate matter (PM) is one of air pollutants, and its aerodynamic diameter ranges from 0.001 to $100 \mu \mathrm{m}$. In particular, the diameter of PM2.5 is small, and can penetrate deep into the lungs. PM is the toxic compounds of polyaromatic hydrocarbons and heavy metals, and causes diseases in the respiratory and cardiac system of humans, which has increased people's attention to PM (Leonard et al., 2016; Popek et al., 2015; Xing et al., 2016). Climate change results in atmospheric stagnation and more frequent atmospheric inversion in the northern hemisphere in winter, increasing the concentration of PM2.5 (Chen et al., 2017).

As over $80 \%$ of people living in this modern society spend most of their time in indoor spaces, the importance of indoor air quality as well as outdoor air quality has also increased recently (Firdaus and Ahmad, 2011; Kim et al., 2018). The level of PM in the indoor air increases as PM generated in outdoor spaces moves into indoor spaces or as PM emitted from indoor pollution sources (Pettit et al.,

\footnotetext{
This study was supported by the research project of the Rural Development Administration (PJ01319804).

Received: November 8, 2019, Revised: November 14, 2019, Accepted: November 24, 2019

First author: Deokjoo Son, djson@korea.kr, (D) https://orcid.org/0000-0003-0508-6619

*Corresponding author: Kwang Jin Kim, kwagnjin@korea.kr, (B) https://orcid.org/0000-0002-2549-9720
} 
2017). For this reason, it is essential to make efforts to reduce the concentration of PM in indoor spaces for the health of people in modern society, and the importance of research on this has also increased.

Plant leaves play a role as a biofilter, and are known to be effective in removing heavy metals (mercury, lead), sulfur dioxide, hydrogen fluoride (HF), volatile organic compounds (VOCs), and PM in the air (Kim et al., 2008; Liu et al., 2012). Plant leaves remove particulate matter through the following mechanisms: 1) adsorption of PM through interactions between PM and plant leaves (Perini et al., 2017); 2) absorption of PM by leaves (Shahid et al., 2017); and 3) fallout of particulate matters on the leeward side of the vegetation (Liu et al., 2012). The ability of plants to remove PM significantly differs depending on the density, type and arrangement of plants (Tong et al., 2016), the characteristics of leaves (roughness of leaf surface, leaf inclination, stomatal density, diameter and conductivity, unit leaf area, wax layer, hair, trichomes, etc.; Qiu et al., 2009; Räsänen et al., 2013). In addition, the characteristics of plant leaves affect the deposition and dispersion of PM particles (Janhäll, 2015). For this reason, examining the characteristics and structure of leaves of individual plant types is an important process for understanding differences in the PM removal efficiency of plants.

Previous studies have mainly focused on how much PM in the air outdoor plants such as street trees and the leaves of biowall plants can adsorb (Beckett et al., 1998; Cho et al., 2017; Liu et al., 2012; Sæbø et al., 2012). Wang (2011) compared the amount of PM removed by 10 species of trees planted along two expressways, and reported that the amount significantly differed depending on the species of plants. A large-scale study reported that when the coverage rate of trees increased to $1 / 4$ of UK conurbations, the concentration of PM2.5 is reduced by $2-10 \%$ (McDonald et al., 2007). A study on comparison of the amount of PM removed by needleleaf and broadleaf trees reported that needleleaf trees accumulated PM more efficiently than broadleaf trees (Chen et al., 2017), but another study reported that needleleaf trees are vulnerable to the high salt concentration observed along streets in the winter, and that their removal efficiency decreases (Sæbø et al., 2012). Many studies have been also conducted to examine how much PM was accumulated on leaves depending on the micromorphology of leaves (wax, cuticle, stoma, hair, trichome, etc.; Räsänen et al., 2013; Sæbø et al., 2012), but results are still conflicting. For instance, it has been known that the rougher the surface of plant leaves, the more efficiently PM is removed, but Sæbø et al. (2012) reported that there was no correlation between the roughness of plant leaves and the amount of PM accumulated on leaves. The chemical composition of the wax layer, not its content, affects the reduced amount of PM (Jouraeva et al., 2002). Earlier studies mostly focused on outdoor plants such as arbores and shrubs, but there is almost no study that discussed differences in the PM removal efficiency of plants depending on the species of plants, the shape of leaves, the structure of the abaxial leaf surface, the wax layer of leaves, etc. for improving the quality of the indoor air like this study.

This study aimed to identify differences in the PM removal efficiency of plants depending on their species, the morphological characteristics of leaves (big leaf, small leaf, compound leaf, needle leaf), and the microscopic structure of the abaxial leaf surface. Specifically, out of 12 species of plants, those that showed a high removal efficiency were selected, and differences in their PM removal efficiency depending on the morphological characteristics of leaves were identified. This study also examined their correlation with their PM removal efficiency and the micromorphology of leaves such as wax layer and the microscopic structure of the abaxial leaf surface.

\section{Research Methods}

\section{Calculation of leaf area and observation of the abaxial leaf surface}

Depending on the shape of plants, 3 species of each shape, a total of 12 species, were selected as follows: needle leaf (Sciadopitys verticillata, Pinus bungeana Zucc., Picea glauca 'Conica'); compound leaf (Nandina domestica Thunb., Pachira aquatica Aubl., Schefflera arboricola); small leaf (Ardisia crenata, Pittosporum tobira, Ficus benjamina L.); and big leaf (Dieffenbachia 'Marianne', 
Philodendron erubescens, Quercus dentata).

The leaf area of plants was measured using a leaf area meter (LI-3100, LI-COR, USA) based on the method of Räsänen et al. (2013). The leaf area of needleleaf trees was additionally calculated using Equation 1(Lee et al., 2006), where, the volume of needle leaves was calculated by measuring the volume of water that was increased when 50 needle leaves were put into a measuring cylinder filled with water.

$$
\mathrm{A}=2 l\left(1+\frac{\pi}{n}\right) \cdot \sqrt{\frac{v n}{\pi l}}
$$

where A: leaf area, $l$ : length of needle leaf, $v$ : volume of needle leaves, $n$ : number of needle leaves

The structure of the abaxial leaf surface, the cross section of leaves, and stomata were observed using a scanning electron microscope (SU3500, Hitachi, Japan).

\section{Method of measuring the amount of PM reduced by plants}

PM particles were dispersed with compressed air, and particles of over PM10 were fallen for 3 hours. Approximately $300 \mu \mathrm{g} \cdot \mathrm{m}^{-3}$ of PM2.5 was injected to a chamber filled with plants, and a fan within the chamber was operated for 30 seconds. After 4 hours, the removed amount of PM was measured (DustTrak DRX Aerosol Monitor 8533, TSI, USA). This process was repeated 4 or 7 times depending on the type of experiments.

\section{Method of measuring the weight of the wax layer on the surface of leaves}

To ensure the total leaf area of each plant species is $100 \mathrm{~cm}^{2}$, six samples were collected, and the foreign substances on the collected samples were removed with distilled water, and the moisture on the surface of leaves was evaporated within a fume hood for 2 hours. An empty beaker was prepared, and its weight was measured. Chloroform $40 \mathrm{~mL}$ was poured into the beaker, and the collected leaves were dipped in the beaker for 40 seconds to dissolve their wax layer. After 40 seconds, the leaves were removed, and chloroform within the beaker was completely evaporated for 1 day. The weight of the beaker with the dissolved wax left was measured, and the weight of the wax layer was calculated by subtracting the weight of an empty beaker from the measured weight.

\section{Results and Discussion}

The amount of PM2.5 removed differed depending on the species of plants, but there was no difference observed between the different shapes of leaves (Fig. 1). Out of the

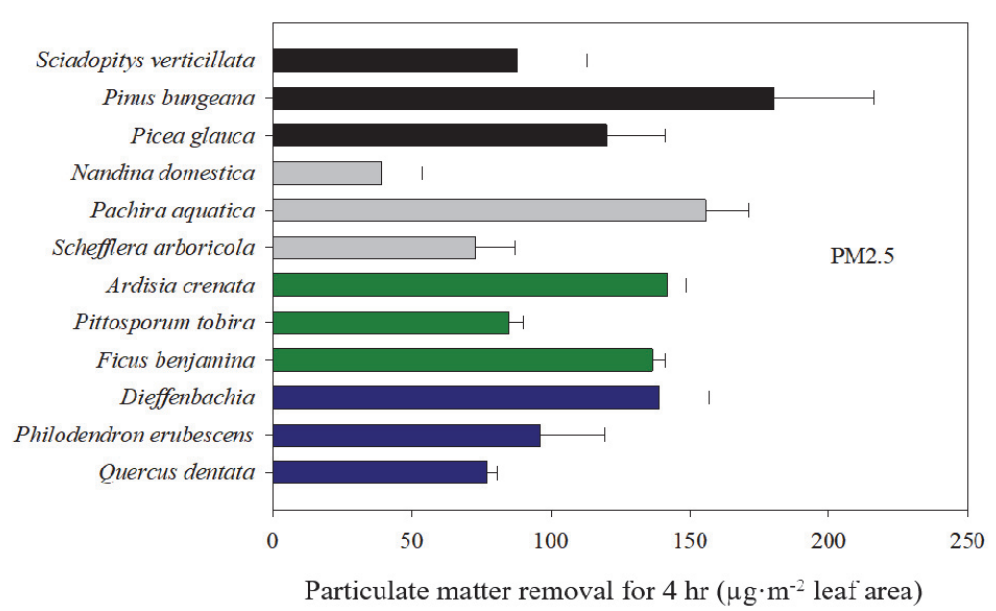

Fig. 1. Removed amount of particulate matter (PM2.5) on leaves of 12 plant species during 4 hours. Data are mean \pm SE. Colored bars represent four different groups of plants; black= needle leaf plants; gray= compound leaf plants; green= small leaf plants; blue=big leaf plants. 
12 species measured in this study, the amount of PM2.5 removed by Pinus bungeana Zucc. was the highest $\left(180.1 \mu \mathrm{g} \cdot \mathrm{m}^{-2}\right.$ leaf area), while that of PM2.5 removed by Nandina domestica Thunb., the lowest $\left(38.8 \mu \mathrm{g} \cdot \mathrm{m}^{-2}\right.$ leaf area). Out of the needleleaf plants, that of PM2.5 removed by Pinus bungeana Zucc. was the highest $\left(180.1 \mu \mathrm{g} \cdot \mathrm{m}^{-2}\right.$ leaf area), and out of the compound leaf plants, that of PM2.5 removed by Pachira aquatica Aubl. was the highest $\left(155.8 \mu \mathrm{g} \cdot \mathrm{m}^{-2}\right.$ leaf area). Out of the small leaf plants, the amount of PM2.5 removed by Ardisia crenata and Ficus benjamina L. was similar $\left(142.0 \mu \mathrm{g} \cdot \mathrm{m}^{-2}\right.$ leaf area and $136.4 \mu \mathrm{g} \cdot \mathrm{m}^{-2}$ leaf area respectively). Out of the big leaf plants, that of PM2.5 removed by Dieffenbachia 'Marianne' was the highest $\left(139.1 \mu \mathrm{g} \cdot \mathrm{m}^{-2}\right.$ leaf area).

The amount of PM10 removed differed depending on the species of plants, and there were also differences between the shapes of plants (Fig. 2). Out of the 12 species measured in this study, the amount of PM10 removed by Pinus bungeana Zucc. was the highest $\left(528.5 \mu \mathrm{g} \cdot \mathrm{m}^{-2}\right.$ leaf area), while that of PM10 removed by Nandina domestica Thunb., the lowest $\left(28.8 \mu \mathrm{g} \cdot \mathrm{m}^{-2}\right.$ leaf area). Out of the needle leaf plants, that of PM10 removed by Pinus bungeana Zucc. was the highest (528.5 $\mu \mathrm{g} \cdot \mathrm{m}^{-2}$ leaf area), and out of the compound leaf plants, that of PM10 removed by Pachira aquatica Aubl. was the highest $\left(162.6 \mu \mathrm{g} \cdot \mathrm{m}^{-2}\right.$ leaf area). Out of the small leaf plants, the amount of PM10 removed by Ardisia crenata and Ficus benjamina L. was similar $\left(140.8 \mu \mathrm{g} \cdot \mathrm{m}^{-2}\right.$ leaf area and $140.9 \mu \mathrm{g} \cdot \mathrm{m}^{-2}$ leaf area respectively). Out of the big leaf plants, the amount of PM10 removed by Dieffenbachia 'Marianne' was the highest $\left(197.6 \mu \mathrm{g} \cdot \mathrm{m}^{-2}\right.$ leaf area). That is, in terms of the species of plants, the amount of both PM10 and PM2.5 removed by Pinus bungeana Zucc. was the highest, and that of both PM10 and PM2.5 removed by Nandina domestica Thunb. was the lowest. In terms of the shape of leaves, that of PM10 and PM2.5 removed by needle leaf plants was the highest.

Plants were divided based on their leaf shapes, and the amount of PM2.5 and PM10 removed per hour was measured. The amount of PM10 removed by needleleaf plants was higher $\left(89.5 \mu \mathrm{g} \cdot \mathrm{h}^{-1} \cdot \mathrm{m}^{-2}\right.$ leaf area) than other types of plants, but there was no significant difference observed in the amount of PM2.5 depending on the leaf shape of plants (Fig. 3). The amount of PM10 removed by needleleaf plants was the highest $\left(89.5 \mu \mathrm{g} \cdot \mathrm{h}^{-1} \cdot \mathrm{m}^{-2}\right.$ leaf area), followed by big leaf plants $\left(34.7 \mu \mathrm{g} \cdot \mathrm{h}^{-1} \cdot \mathrm{m}^{-2}\right.$ leaf area), small leaf plants $\left(31.4 \mu \mathrm{g} \cdot \mathrm{h}^{-1} \cdot \mathrm{m}^{-2}\right.$ leaf area), and compound leaf plants $\left(21.0 \mu \mathrm{g} \cdot \mathrm{h}^{-1} \cdot \mathrm{m}^{-2}\right.$ leaf area). In terms of PM2.5, there was no significant difference, but the amount of PM2.5 removed by needleleaf plants was the

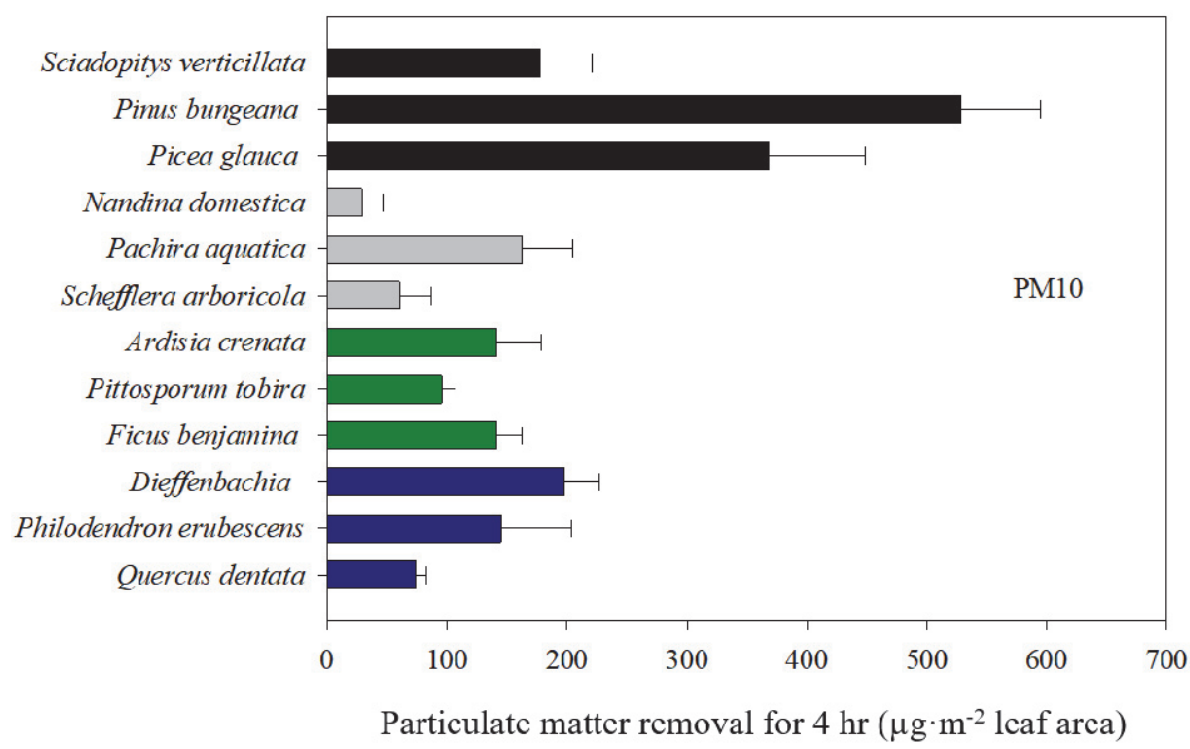

Fig. 2. Removed amount of particle matter (PM10) on leaves of 12 plant species during 4 hours. Data are mean \pm SE. Colored bars represent four different groups of plants: black= needle leaf plants; gray= compound leaf plants; green= small leaf plants; blue= big leaf plants. 
highest $\left(32.3 \mu \mathrm{g} \cdot \mathrm{h}^{-1} \cdot \mathrm{m}^{-2}\right.$ leaf area), followed by small leaf plants $\left(30.3 \mu \mathrm{g} \cdot \mathrm{h}^{-1} \cdot \mathrm{m}^{-2}\right.$ leaf area $)$, big leaf plants $\left(26.0 \mu \mathrm{g} \cdot \mathrm{h}^{-1} \cdot \mathrm{m}^{-2}\right.$ leaf area), and compound leaf plants $\left(22.3 \mu \mathrm{g} \cdot \mathrm{h}^{-1} \cdot \mathrm{m}^{-2}\right.$ leaf area).

Since the ability of plants to remove PM differs depending on the microstructure of leaves, the ability differs depending on the species of plants (Liu et al., 2012). The results of this study showed clear differences in the amount

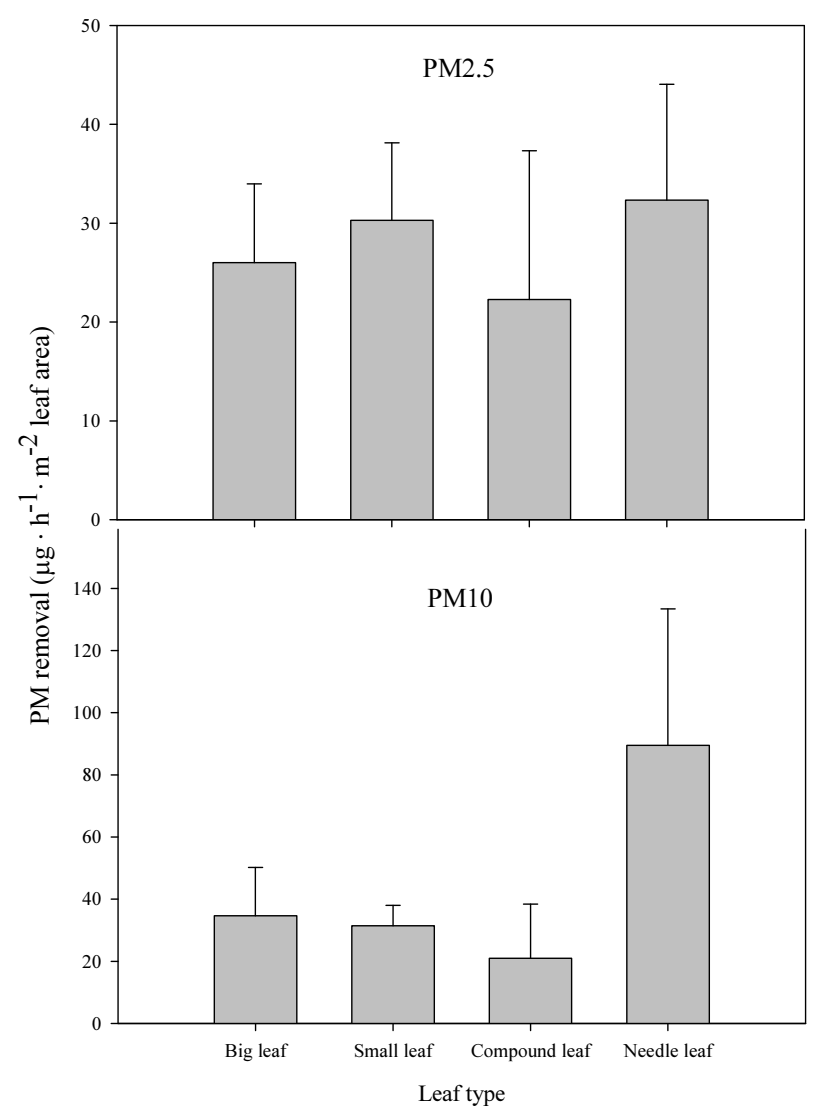

Fig. 3. Comparison of the removal amount of PM2.5(top) and PM10(bottom) by different types of leaves of plant species. Data are mean \pm SE. of PM10 and PM2.5 removed depending of the species of plants and the shape of leaves. That is, the amount of PM10 removed by needleleaf plants was significantly higher than other broadleaf plants, but there was almost no difference in the amount of PM10 removed between big, small and compound leaf plants. Weerakkody et al. (2018a) reported that the amount of PM removed by plants differed depending on the size of leaves, and that that removed by small leaf plants was higher than that removed by big leaf plants. However, in this study, the removed amount of PM did not differ depending on the size of leaves, but in terms of the shape of leaves, the amount removed by needle leaf plants was the highest compared to big, small and compound leaves.

Differences in the leaf area of needleleaf plants depending on the method of calculation were also examined, the total leaf area of Pinus bungeana Zucc. and Picea glauca 'Conica' calculated using the method for broadleaf plants $\left(0.10 \mathrm{~m}^{2}\right.$ and $0.34 \mathrm{~m}^{2}$ respectively) increased by 1.7 and 1.6 times compared to their total leaf area calculated using the method for needleleaf plants $\left(0.17 \mathrm{~m}^{2}\right.$ and $0.54 \mathrm{~m}^{2}$ respectively). On the other hand, the total leaf area of Sciadopitys verticillata calculated using the method for broadleaf plants $\left(0.29 \mathrm{~m}^{2}\right)$ was reduced by 0.7 times compared to its total leaf area calculated using the method for needleleaf plants $\left(0.21 \mathrm{~m}^{2}\right.$; Table 1$)$.

The amount of PM2.5 reduced by needleleaf trees significantly differed depending on the method of calculating leaf area (Fig. 4). When the method of calculating the leaf area of broadleaf trees was applied, the amount of PM reduced by Pinus bungeana Zucc. was the highest $\left(180.1 \mu \mathrm{g} \cdot \mathrm{m}^{-2}\right.$ leaf area), followed by Picea glauca 'Conica' $\left(120.1 \mu \mathrm{g} \cdot \mathrm{m}^{-2}\right.$ leaf area) and Sciadopitys verti-

Table 1. Comparison of leaf areas of three conifers measured by a different formula

\begin{tabular}{ccc}
\hline & \multicolumn{2}{c}{ Leaf area $\left(\mathrm{m}^{2}\right)$} \\
\cline { 2 - 4 } & ${\text { Formula } \mathrm{A}^{\mathrm{z}}}^{\text {Formula B }^{\mathrm{y}}}$ \\
\hline Sciadopitys verticillata & 0.29 & 0.21 \\
Pinus bungeana & 0.10 & 0.17 \\
Picea glauca & 0.34 & 0.54 \\
\hline
\end{tabular}

${ }^{\mathrm{z}}$ Formula A to measure the broadleaf area: leaf area = width $(\mathrm{m}) \mathrm{x}$ length $(\mathrm{m})$.

${ }^{\mathrm{y}}$ Formula B to measure the needleleaf area: $\mathrm{A}=2 l\left(1+\frac{\pi}{n}\right) \cdot \sqrt{\frac{v n}{\pi l}}$, where A: leaf area, $l$ : length, $v$ : volume, $n$ : number of needleleaf. 
cillata $\left(87.8 \mu \mathrm{g} \cdot \mathrm{m}^{-2}\right.$ leaf area). However, when the method of calculating the leaf area of needleleaf trees was applied, the amount of PM reduced by Sciadopitys verticillata was the highest $\left(121.7 \mu \mathrm{g} \cdot \mathrm{m}^{-2}\right.$ leaf area), followed by Pinus bungeana Zucc. $\left(103.1 \mu \mathrm{g} \cdot \mathrm{m}^{-2}\right.$ leaf area), and Picea glauca 'Conica' $\left(75.7 \mu \mathrm{g} \cdot \mathrm{m}^{-2}\right.$ leaf area). For this reason, when the method of calculating the leaf area of needleleaf trees was applied to Pinus bungeana Zucc. and Picea glauca 'Conica', their leaf area increased, and the amount of PM reduced by them per unit leaf area decreased. In the case of Sciadopitys verticillate, when the method of calculating the leaf area of needleleaf trees was applied, its leaf area decreased, and thus the reduced amount of PM2.5 per unit leaf area increased.

The weight of the wax layer on the leaf surface of needleleaf plants was higher than other plants (Fig. 5). That of the wax layer on the leaf surface of Sciadopitys verticillata was $43.2 \mathrm{mg} \cdot 100 \mathrm{~cm}^{-2}$ leaf area; Pinus bungeana Zucc., $39.6 \mathrm{mg} \cdot 100 \mathrm{~cm}^{-2}$ leaf area; and Picea glauca 'Conica', $37.1 \mathrm{mg} \cdot 100 \mathrm{~cm}^{-2}$ leaf area. The weight of the

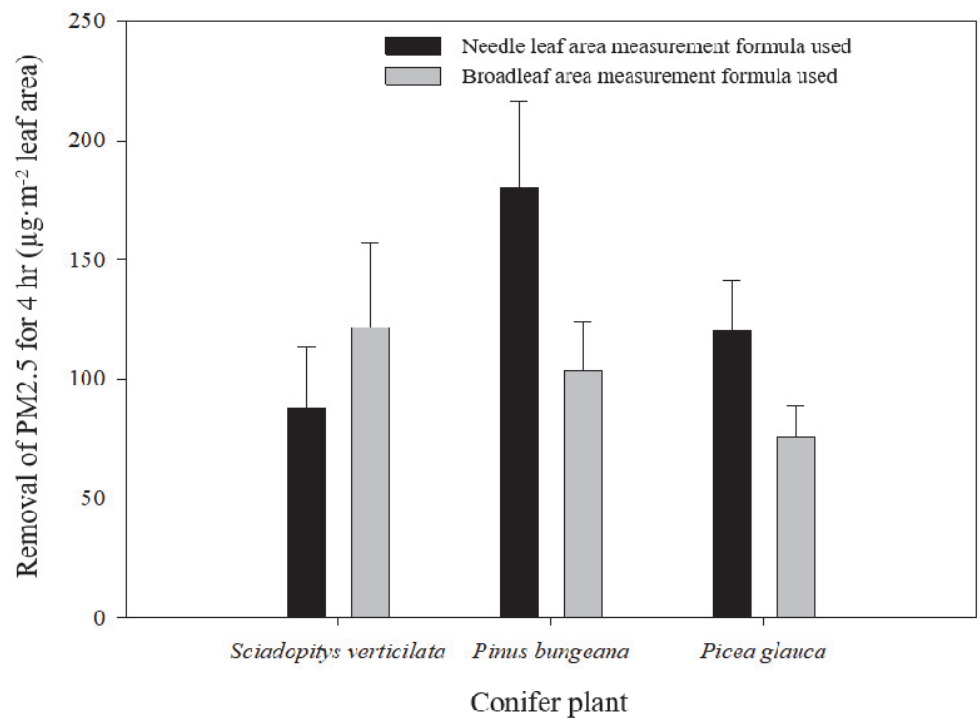

Fig. 4. Differences in PM2.5 removal for 4 hours in three conifers by using different methods of leaf area measurements. Black bars represent PM2.5 removal calculated by using the method of needle leaf area measurement. Gray bars represent PM2.5 removal calculated by using the method of broadleaf area measurment. Data are mean \pm SE.

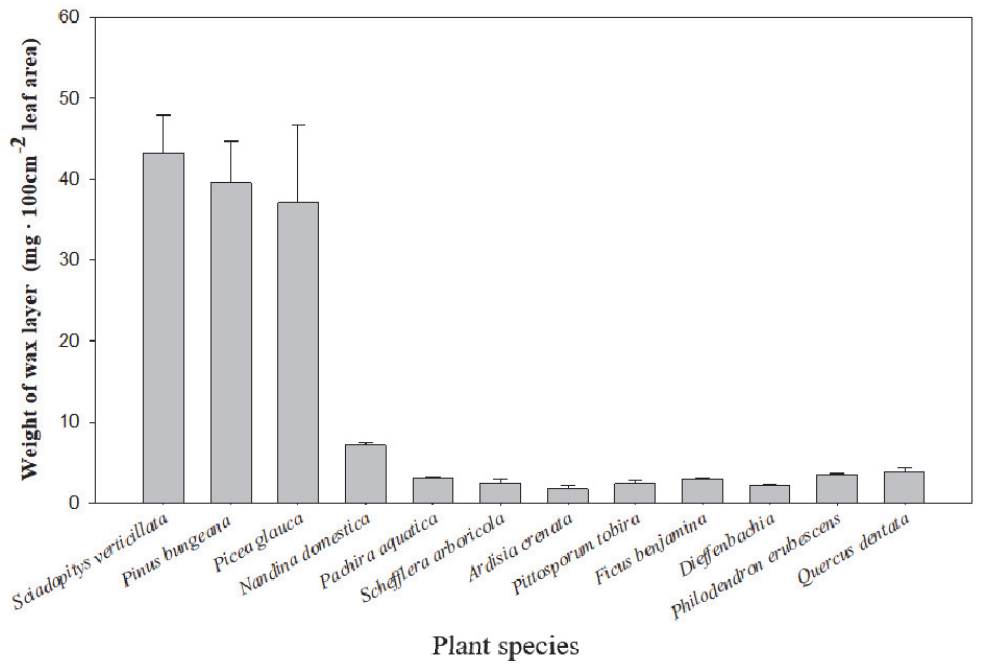

Fig. 5. Weight of wax layer on leaf surface of plants $\left(\mathrm{mg} \cdot 100 \mathrm{~cm}^{-2}\right.$ leaf area). Data are mean \pm SE. 
wax layer of Sciadopitys verticillata $\left(43.2 \mathrm{mg} \cdot 100 \mathrm{~cm}^{-2}\right.$ leaf area) was found to be about 6 times higher than that of the wax layer of Nandina domestica Thunb., one of the measured compound leaf plants, $\left(7.1 \mathrm{mg} \cdot 100 \mathrm{~cm}^{-2}\right.$ leaf area), and about 24 times higher than that of the wax layer of Ardisia crenata, one of the measured small leaf plants, $\left(1.8 \mathrm{mg} \cdot 100 \mathrm{~cm}^{-2}\right.$ leaf area).

The amount of PM10 removed by needleleaf plants was significantly higher than other broadleaf plants, and the content of the wax layer on the surface of needleleaf plants was higher by at least 6 times and up to 24 times than other broadleaf plants. These results coincided with those of other studies that reported that the higher the content of the wax layer, the more efficiently PM can be reduced (Sæbø et al., 2012). Uzu et al. (2010) also reported that PM tended to be adsorbed mainly to the trichomes and the wax layer of leaves. The wax layer on the surface of leaves is non-hydrophilic, and thus can absorb more non-hydrophilic particles in the air, and selectively block hydrophilic particles (Perini et al., 2017). In addition, PM that contains heavy metals is captured by the wax layer on the surface of leaves, and is diffused into the leaves (Shahid et al., 2017). The results of this study indicate that since the content of the way layer on the surface of needleleaf plants was higher than broadleaf plants, more PM was reduced.

Those that showed a high removal efficiency of PM included Pachira aquatica Aubl., Ardisia crenata, and Dieffenbachia 'Marianne', and the structure of the abaxial leaf surface had many large wrinkles (Fig. 6A). Those that showed a medium removal efficiency of PM included Pittosporum tobira, Ficus benjamina L., and Philodendron erubescens, and the structure of the abaxial leaf surface was flat and smooth (Fig. 6B). Those that showed a low removal efficiency of PM included Nandina domestica Thunb., Schefflera arboricola, and Quercus dentate, and the structure of the abaxial leaf surface had many fine hairs (Fig. 6C).

The more and larger wrinkles the surface of leaves has, the larger the leaf area of plants that contacts with PM (Zhang et al., 2017). In addition, the rougher the surface of leaves, the higher the number of ridges, which is more effective in capturing PM (Weerakkody et al., 2018a).
Since PM adsorbed on the smooth surface of leaves is highly likely to be dispersed again, and thus its removal efficiency decreases over time (Davidson and $\mathrm{Wu}, 1990$ ). Similar to the results of this study, Wang et al. (2013) also reported that the rougher the surface of leaves of broadleaf trees, and the deeper wrinkles they had, the larger amount of PM2.5 was reduced.

Schefflera arboricola and Nandina domestica Thunb. that had hairs on the abaxial leaf surface removed the lowest amount of PM. Perini et al. (2017) also reported that Phlomis fruticose that had many hairs on the surface of leaves removed a lower amount of PM than other plants that had no hair on the surface of leaves. On the contrary, another study reported that plants that have hairs on the surface of leaves have a larger leaf area that can contact with PM, and that hairs prevent the PM captured on the
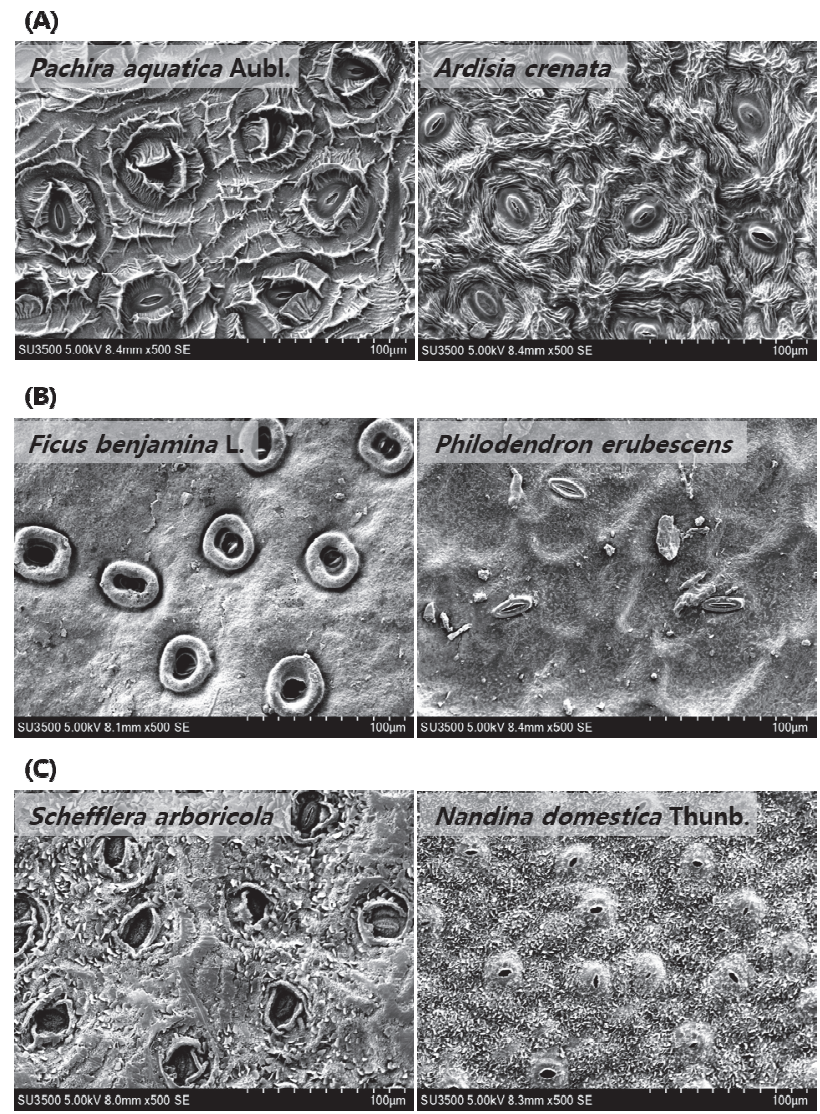

Fig. 6. Scanning electron microscope pictures of abaxial leaf surface (A) with high PM removal efficiency (Pachira aquatica Aubl., Ardisia crenata), (B) with medium PM removal efficiency (Ficus benjamina L., Philodendron erubescens), and (C) with low PM removal efficiency (Schefflera arboricola, Nandina domestica Thunb.). 
surface of leaves from being dispersed again, and significantly increased the removal efficiency (Weerakkody et al., 2018b). Therefore, it is difficult to conclude whether the existence of hairs affects the reduction of PM positively or negatively, and it is necessary to conduct follow-up studies on the length of hair, the density of hairs per unit area and the chemical compounds, targeting various plants (Perini et al., 2017).

The location and shape of stomata varied depending on the species of plants (Fig. 7). The cross section of Sciadopitys verticillata was flat with the naked eye, but when it was observed with a scanning electron microscope, there were curves but the middle was sunken as shown in Fig. 7A. The shape of stomata of Sciadopitys verticillate was not general, but papillae were thickly distributed on a certain area of the abaxial leaf surface. However, no stoma or papilla was observed on the adaxial leaf surface of Sciadopitys verticillata (Fig. 7B, C, J).

The cross section of Pinus bungeana Zucc. had, either seen with the naked eye or a scanning electron microscope, a projected area in the middle of the adaxial leaf surface, and the abaxial leaf surface was round (Fig. 7D). The stomata of Pinus bungeana Zucc. were distributed in a row both on the adaxial and abaxial leaf surface (Fig. 7E, F, J).

The cross section of Picea glauca 'Conica' had a pentagonal shape with the naked eye, but it was difficult to clearly distinguish the adaxial and abaxial leaf surface with an electron microscope (Fig. 7G). The stomata of Picea glauca 'Conica' were evenly distributed on a certain area of the mesophyll of leaves (Fig. 7H, I, J).

In terms of the shape of leaves, the amount of PM10 removed by needleleaf trees was significantly higher than plants that had other shapes of leaves. In general, evergreen needleleaf trees are known to capture more PM than other broadleaf trees (Tallis et al., 2011). The stomata of the needleleaf trees observed in this study showed various shapes unlike those of broadleaf trees, Pinus bungeana Zucc. and Picea glauca 'Conica' had stomata both on the adaxial and abaxial leaf surface, and stomatal papillae were densely distributed on the abaxial leaf surface of Sciadopitys verticillata. Haworth and McElwain (2008) reported that the stomata of Sciadopitys verticillata were observed on the sunken areas of leaves in the form of papillae, which increases water repellency. The stomata of Pinus bungeana Zucc. were regularly distributed in a row both on the adaxial and abaxial leaf surface, and had an oval shape with no hair observed on the surface of leaves (Zhang et al., 2017). While there is a little correlation between the roughness of the surface of leaves and the reduced amount of PM2.5 in the case of needleleaf trees (Wang et al., 2013), the reduced amount of PM2.5 is known to be affected more by the structural characteristics of the surface of leaves such as stoma, wax layer and cuticle (Zhang et al., 2017).
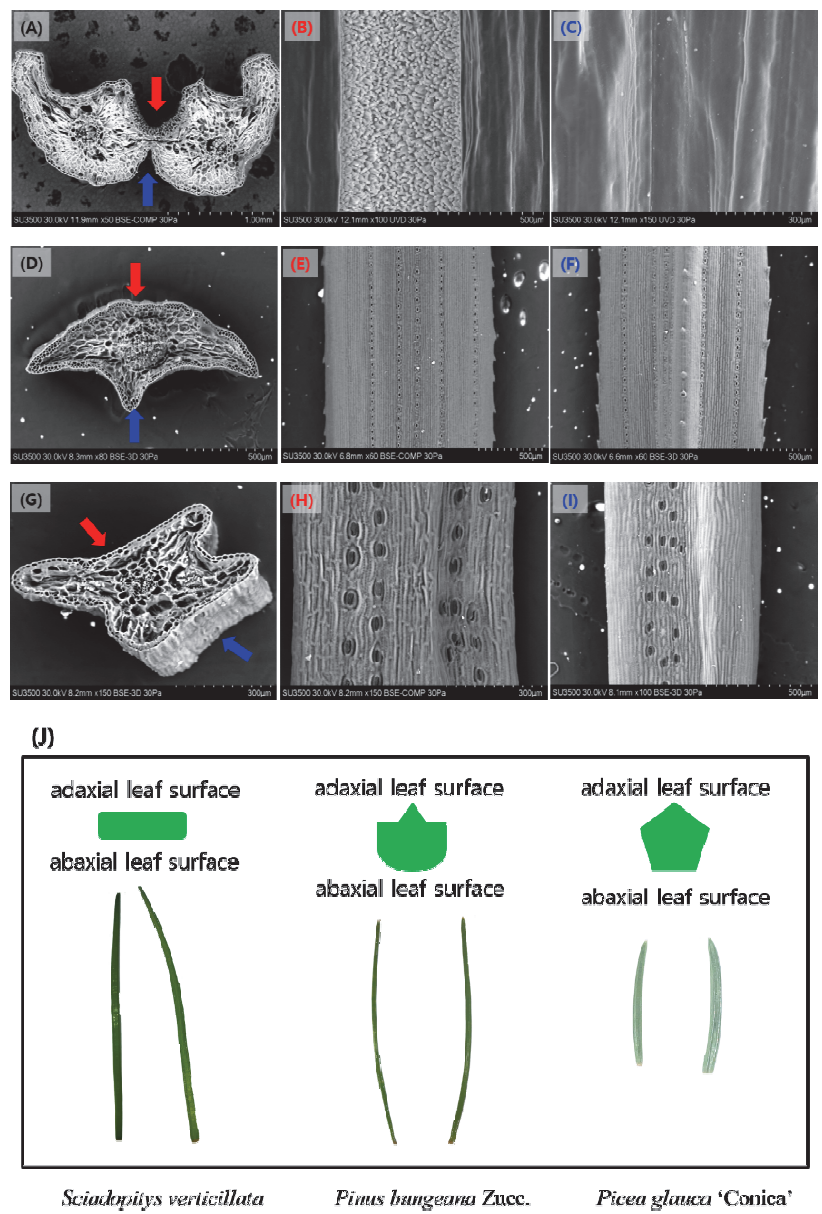

Fig. 7. Cross section and scanning electron microscope pictures of stomata of the needle leaf. (A) cross section of Sciadopitys verticillata, (B) abaxial leaf surface of Sciadopitys verticillata, (C) adaxial leaf surface of Sciadopitys verticillata, (D) cross section of Pinus bungeana Zucc., (E) abaxial leaf surface of Pinus bungeana Zucc., (F) adaxial leaf surface of Pinus bungeana Zucc., (G) cross section of Picea glauca 'Conica', (H) abaxial leaf surface of Picea glauca 'Conica', (I) adaxial leaf surface of Picea glauca 'Conica', (J) visual observation of needleleaf plants. Red arrows and blue arrows represent abaxial and adaxial leaf surface, respectively. 


\section{Conclusion}

This study aimed to identify differences in the PM removal efficiency of plants depending on the species of plants, the morphological characteristics of leaves (big leaf, small leaf, compound leaf, needle leaf) and the structure of the abaxial leaf surface. There were differences in the reduced amount of PM between big, small, compound and needle leaves, and in particular, the amount of PM10 removed by needleleaf plants was higher than other broadleaf plants. The amount of PM2.5 removed by needleleaf plants, however, did not show significant differences compared to other broadleaf plants. These results can be attributed to the fact that needleleaf plants showed the higher content of the wax layer than broadleaf plants, and thus that the wax layer adsorbed many PM. In addition, since stomata are distributed evenly or in the form of papillae on the adaxial and abaxial leaf surface of needleleaf plants, the leaf area of leaves that can contact with PM increases and shows a higher removal efficiency. The abaxial leaf surface of broadleaf plants with a high PM removal efficiency had steep curves and wrinkles, while the abaxial leaf surface of broadleaf plants with a low PM removal efficiency tended to have many hairs. These differences in the microstructure of leaves seemed to affect the PM removal efficiency of plants. It will be necessary to increase the number of species of needleleaf trees in follow-up studies in order to identify the mechanism behind the differences in the removed amount of PM10 and PM2.5, and the unique structure of the surface of leaves of needleleaf trees, and stomata need to be examined. When PM contacts with hairs on the surface of leaves, electrostatic repulsive force can be generated near the pointed area of hairs, and this phenomenon can affect the PM removal efficiency of plants. In follow-up studies, it will be necessary to additionally research the density and length of hairs and the chemical compounds of hairs in order to examine electrostatic repulsive force generated between the hairs on the surface of leaves and PM.

\section{References}

Chen, L., C. Liu, L. Zhang, R. Zou, and Z. Zhang. 2017. Variation in tree species ability to capture and retain airborne fine particulate matter (PM 2.5). Sci. Rep. 7:3206. https://doi.org/10.1038/s41598-017-03360-1

Cho, M.G., E.J. Jin, E.J. Bae, K.S. Lee, H.S. Moon, and M.R. Huh. 2017. Absorption ability of particulate matter in leaves of street trees in Jinju city. J. People Plants Environ. 20(5):431-440. https://doi.org/10.11628/ksppe. 2017.20.5.431

Davidson, C.I. and Y.L. Wu. 1990. Dry deposition of particles and vapors. In: S.E. Lindberg, A.L. Page, and S.A. Norton (Eds.), Acidic precipitation: sources, deposition, and canopy interactions (pp. 103-216). New York, NY: Springer. https://doi.org/10.1007/978-1-4612-4454-7_5

Firdaus, G. and A. Ahmad. 2011. Indoor air pollution and self-reported diseases - a case study of NCT of Delhi. Indoor Air 21(5):410-416. https://doi.org/10.1111/j.1600 $-0668.2011 .00715 . x$.

Haworth, M. and J. McElwain. 2008. Hot, dry, wet, cold or toxic? Revisiting the ecological significance of leaf and cuticular micromorphology. Palaeogeogr. Palaeoclimatol. Palaeoecol. 262:79-90. https://doi.org/10.1016/j.palaeo. 2008.02.009

Janhäll, S. 2015. Review on urban vegetation and particle air pollution - Deposition and dispersion. Atmos. Environ. 105:130-137. https://doi.org/10.1016/j.atmosenv.2015.0 1.052

Jouraeva, V.A., D.L. Johnson, J.P. Hassett, and D.J. Nowak. 2002. Differences in accumulation of PAHs and metals on the leaves of Tiliaxeuchlora and Pyrus calleryana. Environ. Pollut. 120(2):331-338. https://doi.org/10.1016 /S0269-7491(02)00121-5

Kim, K., M. Kil, J. Song, E. Yoo, K. Son, and S.J. Kays. 2008. Efficiency of volatile formaldehyde removal by indoor plants: Contribution of aerial plant parts versus the root zone. J. Am. Soc. Hortic. Sci., 133(4): 521-526. https://doi.org/10.21273/JASHS.133.4.521

Kim, K.J., M. Khalekuzzaman, J.N. Suh, H.J. Kim, C. Shagol, H.H. Kim, and H.J. Kim. 2018. Phytoremediation of volatile organic compounds by indoor plants: a review. Hortic. Environ. Biotechnol. 59(2):143-157. https://doi.org/10.1007/s13580-018-0032-0 
Lee, D.K., Y.S. Kim, and K.C. Kwon. 2006. Biomass and energy content of Pinus densiflora stand in Mt. Wolak, Chungbuk Province. J. Korean For. Energy 25(1):24-30.

Leonard, R.J., C. McArthur, and D.F. Hochuli. 2016. Particulate matter deposition on roadside plants and the importance of leaf trait combinations. Urban For. Urban Green. 20:249-253. https://doi.org/10.1016/j.ufug.2016.09.008

Liu, L., D. Guan, and M.R. Peart. 2012. The morphological structure of leaves and the dust-retaining capability of afforested plants in urban Guangzhou, South China. Environ. Sci. Pollut. Res. Int. 19(8):3440-3449. https://doi.org/10.1007/s11356-012-0876-2

McDonald, A.G., W.J. Bealey, D. Fowler, U. Dragosits, U. Skiba, R.I. Smith, R.G. Donovan, H.E. Brett, C.N. Hewitt, and E. Nemitz. 2007. Quantifying the effect of urban tree planting on concentrations and depositions of PM10 in two UK conurbations. Atmos. Environ. 41(38): 8455-8467. https://doi.org/10.1016/j.atmosenv.2007.07.025

Perini, K., M. Ottelé, S. Giulini, A. Magliocco, and E. Roccotiello. 2017. Quantification of fine dust deposition on different plant species in a vertical greening system. Ecol. Eng. 100:268-276. https://doi.org/10.1016/j.ecolen g.2016.12.032

Pettit, T., P.J. Irga, P. Abdo, and F.R. Torpy. 2017. Do the plants in functional green walls contribute to their ability to filter particulate matter? Build. Environ. 125: 299-307. https://doi.org/10.1016/j.buildenv.2017.09.004

Popek, R., H. Gawrońska, and S.W. Gawroński. 2015. The level of particulate matter on foliage depends on the distance from the source of emission. Int. J. Phytoremediation 17(12):1262-1268. https://doi.org/10.1080/15226514.20 14.989312

Qiu, Y., D. Guan, W. Song, and K. Huang. 2009. Capture of heavy metals and sulfur by foliar dust in urban Huizhou, Guangdong Province, China. Chemosphere 75(4):447-452. https://doi.org/10.1016/j.chemosphere.2008.12.061

Räsänen, J.V., T. Holopainen, J. Joutsensaari, C. Ndam, P. Pasanen, Å. Rinnan, and M. Kivimäenpää. 2013. Effects of species-specific leaf characteristics and reduced water availability on fine particle capture efficiency of trees. Environ. Pollut. 183:64-70. https://doi.org/10.1016/j.envpol.2013.05.015

Sæbø, A., R. Popek, B. Nawrot, H.M. Hanslin, H. Gawronska, and S.W. Gawronski. 2012. Plant species differences in particulate matter accumulation on leaf surfaces. Sci. Total Environ. 427-428:347-354. https://doi.org/10.1016 /j.scitotenv.2012.03.084

Shahid, M., C. Dumat, S. Khalid, E. Schreck, T. Xiong, and N.K. Niazi. 2017. Foliar heavy metal uptake, toxicity and detoxification in plants: A comparison of foliar and root metal uptake. J. Hazard. Mater. 325:36-58. https://doi.org/10.1016/j.jhazmat.2016.11.063

Tallis, M., G. Taylor, D. Sinnett, and P. Freer-Smith. 2011. Estimating the removal of atmospheric particulate pollution by the urban tree canopy of London, under current and future environments. Landsc. Urban Plan. 103(2):129-138. https://doi.org/10.1016/j.landurbplan.2011.07.003

Tong, Z., R.W. Baldauf, V. Isakov, P. Deshmukh, and K. Max Zhang. 2016. Roadside vegetation barrier designs to mitigate near-road air pollution impacts. Sci. Total Environ. 541:920-927. https://doi.org/10.1016/j.scitoten v.2015.09.067

Uzu, G., S. Sobanska, G. Sarret, M. Munõz, and C. Dumat. 2010. Foliar lead uptake by lettuce exposed to atmospheric fallouts. Environ. Sci. Technol. 44(3):1036-1042. https://doi.org/10.1021/es902190u

Wang, H., H. Shi, Y. Li, Y. Yu, and J. Zhang. 2013. Seasonal variations in leaf capturing of particulate matter, surface wettability and micromorphology in urban tree species. Front. Environ. Sci. Eng. 7(4):579-588. https://doi.org/10.1007/s11783-013-0524-1

Wang, Y.C. 2011. Carbon sequestration and foliar dust retention by woody plants in the greenbelts along two major Taiwan highways. Ann. Appl. Biol. 159(2):244-251. https://doi.org/10.1111/j.1744-7348.2011.00494.x

Weerakkody, U., J.W. Dover, P. Mitchell, and K. Reiling. 2018a. Evaluating the impact of individual leaf traits on atmospheric particulate matter accumulation using natural and synthetic leaves. Urban For. Urban Green. 30:98-107. https://doi.org/10.1016/j.ufug.2018.01.001

Weerakkody, U., J.W. Dover, P. Mitchell, and K. Reiling. 2018b. Quantification of the traffic-generated particulate matter capture by plant species in a living wall and evaluation of the important leaf characteristics. Sci. Total Environ. 635:1012-1024. https://doi.org/10.1016/j.scitot env.2018.04.106

Xing, Y.F., Y.H. Xu, M.H. Shi, and Y.X. Lian. 2016. The impact of PM2.5 on the human respiratory system. J. 
Thorac. Dis. 8(1):E69-E74. https://doi.org/10.3978/j.iss n.2072-1439.2016.01.19

Zhang, W., B. Wang, and X. Niu. 2017. Relationship be- tween leaf surface characteristics and particle capturing capacities of different tree species in Beijing. Forests 8(3):92. https://doi.org/10.3390/f8030092 